\title{
Analisis Perbedaan Tarif Rumah Sakit Dan Tarif INA-CBGs Pelayanan Rawat Jalan di RSUD Pasar Rebo Jakarta
}

\author{
Leny Ramadhan ${ }^{1 *}$, MGS Aritonang ${ }^{1}$, Yusi Anggriani ${ }^{1}$ \\ ${ }^{1}$ Magister Ilmu Kefarmasian, Universitas Pancasila, Jakarta, Indonesia \\ *Corresponding Author. E-mail: lenyramadhan57@gmail.com
}

\begin{abstract}
National Health Insurance Program causes an increase in the number of patients; hospital undergoes a decrease in service quality; and differences in the payment system results in tariff differences. The study aimed to find out the difference between hospital tariff and INA-CBGs tariff. It used an observational quantitative method using secondary data. Five hundred patients medical costs with the diagnosis of Hypertensive heart disease with (congestive) heart failure, non-insulin-dependent diabetes mellitus, Atherosclerotic heart disease, Low back pain, and Essential (primary) hypertension were used as the sample in this research with 100 patients for each diagnosis. The results indicated that 313 (62.6\%) patients out of 500 patients had a negative difference and 187 (37.4\%) patients had a positive difference. The difference among hospital tariff and INA-CBGs tariff with hospital tariff greater than the INA-CBGs tariff occurred in the diagnosis of Hypertensive heart disease with (congestive) heart failure of Rp37,563,200 (66.444\%), non-insulin-dependent diabetes mellitus of Rp. 19,525,441 (7.66\%), Atherosclerotic heart disease of Rp13,119,235 or approximately (39.63\%). Moreover, the hospital tariff is lower than the INA-CBGs tariff Low back pain diagnosis is Rp1,026,299 (8.32\%), and Essential (primary) hypertension is Rp2.403.169 (12.38\%). It can be concluded that the negative difference with the hospital tariff is bigger than the INA-CBGs tariff applicable in 2017 with a total difference of Rp.66,778,404.
\end{abstract}

Keywords: Difference, Hospital Tariff, INA-CBGs Tariff, Outpatients

\section{ABSTRAK}

Program Jaminan Kesehatan Nasional menyebabkan peningkatan jumah pasien dan rumah sakit mengalami penurunan mutu pelayanan serta perbedaan sistem pembayaran mengakibatkan terjadinya perbedaan tarif. Penelitian ini bertujuan untuk mengetahui perbedaan tarif rumah sakit dan tarif INA-CBGs. Penelitian ini menggunakan metode kuantitatif secara observasional dengan data sekunder. Sampel Penelitian ini menggunakan biaya pasien dengan diagnose Hypertensive heart disease with (congestive) heart failure, Non-insulin-dependent diabetes mellitus, Atherosclerotic heart disease, Low back pain, dan Essential (primary) hypertension berjumlah 500 dengan 100 pasien untuk tiap - tiap diagnosa. Hasil penelitian menunjukan bahwa 313 $(62,6 \%)$ pasien dari total 500 pasien memiliki elisih negative dan 187 (37,4\%) pasien dengan selisih positif. Perbedaan tarif rumah sakit dan tarif INA- CBGs dengan tarif rumah sakit lebih besar dari tarif INA-CBGs terjadi pada diagnosa Hypertensive heart disease with (congestive) heart failure sebesar Rp. 37.563 .200 (66,444\%), Non-insulin-dependent diabetes mellitus sebesar Rp.19.525.441 (7,66\%), Atherosclerotic heart disease sebesar Rp. 13.119.235 atau sekitar (39,63\%). Dan tarif rumah sakit lebih kecil dari tarif INA-CBGs terjadi pada diagnosa Low back pain sebesar Rp.1.026.299 (8,32\%), dan Essential (primary) hypertension sebesar Rp. 2.403 .169 (12.38\%). Kesimpulan penelitian ini menghasilkan selisih negatif dengan tariff rumah sakit lebih besar dari tariff INA-CBGs yang berlaku pada tahun 2017 dengan total selisih sebesar Rp. 66.778.404.

Keywords: Selisih, Tarif Rumah Sakit, Tarif INA-CBGs, Pasien Rawat Jalan

Submitted: May $3^{\text {rd }} 2021 \mid$ Accepted: December $26^{\text {th }} 2021 \mid$ Published: December $31^{\text {st }} 2021$

\section{Pendahuluan}

Pembiayaan kesehatan telah meningkat setiap tahun disebabkan oleh berbagai faktor seperti penggunaan teknologi kesehatan yang semakin maju, pengenalan obat-obat baru, peningkatan upah tenaga kesehatan profesional, krisis ekonomi yang berkepanjangan, pertumbuhan ekonomi yang lambat dan peningkatan populasi umur tua[1].

Di Indonesia biaya kesehatan cenderung meningkat yang disebabkan oleh berbagai faktor, di antaranya adalah pola penyakit degenerative, orientasi pada pembiayaan kuratif, pembayaran out of pocket (fee for service) secara individual, service yang ditentukan oleh provider, teknologi canggih, perkembangan ilmu kedokteran dan tidak lepas dari inflasi[2].

Dalam upaya memberikan jaminan kesehatan bagi seluruh rakyat Indonesia. Maka pemerintah Indonesia melaksanakannya melalui program Jaminan Kesehatan atau Jaminan Kesehatan Nasional (JKN). Program JKN dimulai dengan diberlakukannya Undang - Undang Nomor 40 Tahun 2004 tentang Sistem Jaminan Sosial Nasional (UU SJSN) 
dan Undang - Undang Nomor 24 Tahun 2011 tentang Badan Penyelenggara Jaminan Sosial (UU BPJS)[3].

Pemerintah menargetkan Indonesia akan mencapai Universal Health Coverage (UHC) atau cakupan kesehatan menyeluruh bagi seluruh penduduk Indonesia. Setiap tahun BPJS Kesehatan menargetkan jumlah penduduk yang menjadi peserta terus bertambah dari 156,7 juta jiwa (2015) ke 188,7 juta (2016), 223 juta (2017), 235,1 juta (2018), dan mencapai 257,5 juta atau seluruh penduduk pada 20194.

Laporan BPJS kesehatan sampai tahun ke-4 pelaksanaan JKN menunjukkan bahwa sebagian besar peserta merasa puas dengan manfaat yang diperoleh dari program JKN juga menunjukkan tingkat kepuasan tinggi serta pelayanan terhadap pasien dianggap cukup baik[5].

Sejak dioperasikannya BPJS kesehatan sebagai pelaksana JKN, berbagai kalangan mengkhawatirkan tarif yang diberlakukan dengan mengacu kepada INA-CBGs (Indonesia Case Base Groups), sebuah model pembayaran yang digunakan BPJS kesehatan untuk mengganti klaim yang ditagihkan oleh rumah sakit.INA-CBGs merupakan sistem pembayaran dengan sistem "paket", berdasarkan penyakit yang diderita pasien. Rumah sakit akan mendapatkan pembayaran berdasarkan tarif INA CBGs yang merupakan rata-rata biaya yang dihabiskan oleh untuk suatu kelompok diagnosis[6].

Melalui INA - CBGs diharapkan dapat meningkatkan mutu dan efisiensi rumah sakit. Manfaat implementasi INA CBGs dalam JKN adalah tarif yang dimaksudkan berbentuk paket yang mencakup seluruh komponen biaya rumah sakit. Berbasis pada data costing dan coding penyakit mengacu pada international Classification of Diseases (ICD) yang disusun WHO[7].

Program JKN membuat rumah sakit pemerintah dan rumah sakit swasta yang bermitra dengan BPJS kesehatan mendapatkan peningkatan jumlah pasien. Kondisi ini membuat pendapatan rumah sakit menjadi meningkat dan mutu pelayanan mengalami penurun8. Rumah sakit menghadapi tantangan mempertahankan mutu layanan ditengah peningkatan kunjungan dan keterbatasan SDM dan sarana serta prasarana yang dimiliki[9].

Tariff adalah bagian atau seluruh biaya penyelenggaraan kegiatan pelayanan di rumah sakit, yang dibebankan kepada pasien sebagai imbalan atau jasa pelayanan yang diterima (Keputusan Menteri Kesehatan Republik Indonesia No.1165/ MENKES/SK/X/2007). Tarif bagi rumah sakit merupakan berapa besar pelayanan yang telah diberikan kepada pasien maka berapa banyak tariff yang didapatkan oleh rumah sakit sesuai dengan peraturan yang ada.

Rumah Sakit Umum Daerah Pasar Rebo (RSUD Pasar Rebo) merupakan salah satu rumah sakit pemerintah yang berlokasi di Jakarta Timur yang memiliki angka kunjungan pasien cukup tinggi. Jumlah kunjungan sekitar 1.000 lebih orang per hari.

Pendapatan RSUD Pasar Rebo antara lain pendapatan usaha dari jasa pelayanan dan pendapatan usaha lainnya. Pendapatan usaha dari jasa layanan terdiri dari penerimaan rawat inap dan pnerimaan rawat jalan, penerimaan instalasi gawat darurat, penerimaan bedah sentral dan penerimaan piutang.

Tujuan dari penelitian ini untuk mengetahui perbedaan tarif rumah sakit dengan tarif INA-CBGs di RSUD Pasar Rebo untuk pasien rawat jalan.

\section{Metode Penelitian}

Metode yang digunakan dalam penelitian ini adalah metode kuantitatif secara observasional. Pengumpulan data secara observasi digunakan untuk mencatat dan mengumpulkan data - data pendukung kemudian membandingkan antara biaya riil rumah sakit dengan tarif yang dibayarkan oleh BPJS. Variabel independen dalam penelitian ini adalah tarif riil RS: Besaran uang tunai (Moneter) yang didapatkan dari rata-rata tariff yang diberikanoleh rumah sakit berdasarkan pelayanan yang diberikan. Tarif INA-CBGs: Besaran uang tunai yang didapatkan dari rata-rata tariff yang diberikan oleh BPJS berdasarkan kelompok klaim. Selisih tariff : Besaran yang uang didapatkan dari pengurangan antaran tariff rumah sakit dengan tariff INA-CBGs. Dalam Penelitian ini, pengambilan sampel dilakukan di RSUD Pasar Rebo pasien rawat jalan tahun 2017 dengan 5 diagnosa tertinggi yaitu Hypertensive heart disease with (congestive) heart failure, Non-insulindependent diabetes mellitus, Low back pain, Atherosclerotic heart disease, dan Essential (primary) hypertension sebanyak 100 pasien untuk tiap diagnosa yang didapatkan dari hasil perhitungan dengan rumus slovin. Kriteria inklusi yaitu pasien BPJS rawat jalan yang termasuk dalam lima diagnosa tertinggi ICD-X, pasien yang memiliki kelengkapan data rekam medis dan rincian data biaya perawatan, dan semua pasien laki laki maupun perempuan dewasa dengan umur 19-70. Kriteria eksklusi yaitu pasien BPJS rawat inap, pasien yang tidak memiliki kelengkapan data perawatan, dan pasien dengan status pulang paksa

\section{Hasil dan Pembahasan \\ Karakteristik pasien}

Berdasarkan data yang diperoleh dari penelitian bahwa didapatkan pasien dengan diagnosa Hypertensive heart disease with (congestive) heart failure (I11.0) sebanyak 23.613 (19,49\%), Non-insulin-dependent diabetes mellitus (E11) sebanyak 19.928 (16,45\%), Low back pain (M54.4) sebanyak $11.415(9,424 \%)$, Atherosclerotic heart disease (I25.1) sebanyak $10.842(8,95 \%)$, dan Essential (primary) hypertension (I10) sebanyak 7,545 (6,22\%).

\section{Perbedaan tarif rumah sakit dan tarif INA-CBGs}

Dalam penelitian ini terdapat lima diagnosa berdasarkan pada ICD-X yang dijadikan sampel. Dalam perhitungan data tabel rata - rata dan presentase dalam penelitian ini menggukan rumus:

$$
\begin{aligned}
& \text { Rata-rata }(\mathrm{m})=\frac{\text { Jumlah data }}{\text { Banyak data }} \\
& \text { Presentase }(\%)=\frac{\text { Jumlah bagian }}{\text { Jumlah total }} \times 100 \%
\end{aligned}
$$

\section{Hypertensive heart disease with (congestive) heart failure}

Hypertensive heart disease with (congestive) heart failure merupakan suatu istilah yang digunakan secara umum untuk penyakit jantung seperti hipertropi ventrikel kiri, penyakit jantung koroner, aritmia jantung dan gagal jantung kongesif yang disebabkan oleh tingginya tekanan darah kronis. Penyebab dari Hypertensive heart disease with (congestive) heart failure adalah hipertensi kronis. Pengobatan hipertensi kronis merupakan terapi yang memerlukan biaya dalam skala besar dan mahal[10]. 
Pada Tabel 1. Memperlihatkan secara total pada diagnosa Hypertensive heart disease with (congestive) heart failure dengan jumlah pasien 100 menghasilkan selisih negatif sebesar Rp.37.563.200 (66,44\%) dengan jumlah kode INACBGs sebanyak empat, 92 pasien $(9,2 \%)$ menghasilkan total tarif rumah sakit lebih besar dan sebanyak 8 pasien dengan tarif INA-CBGs lebih besar. Komponen tagihan rumah sakit yang paling besar adalah penunjang sebesar Rp.28.043.387 (49,60\%), selanjutnya obat sebesar Rp.26.460.213 (46,80\%) dan tindakan sebesar Rp.1.530.000 (2,70\%).

\section{Perbandingan tarif berdasarkan dignosa Non - insulin- dependent diabetes mellitus}

Diabetes tipe II (Non-insulin-dependent diabetes mellitus) yaitu diabetes yang tidak tergantung pada insulin biasanya terjadi sekitar 90-95\% dari penderita diabetes secara keseluruhan. Riset melaporkan bahwa obesitas salah satu factor determinan terjadinya NIDDM sekitar $80 \%$ pasien NIDDM adalah kegemukan. Factor resiko dapat dijumpai pada pasien dengan riwayat keluarga menderita DM adalah resiko yang besar. Pencegahan utama NIDDM adalah mempertahankan adalah mempertahankan berat badan ideal. Pencegahan sekunder berupa program penurunan berat badan, olahraga dan $\operatorname{diet}[12]$.

Tabel 2 memperlihatkan secara total pada diagnosis Non-insulin-dependent diabetes mellitus sebanyak 100 pasien menghasilkan selisih negatif sebesar Rp.19.525.441 (49,96\%) dengan total tujuh kode INA-CBGs yang digunakan dalam pembayaran yaitu $75(7,5 \%)$ pasien yang besaran tarif rumah sakitnya lebih besar daripada tarif INA-CBGs. Sementara 25 $(2,5 \%)$ pasien dengan besaran tarif rumah sakit lebih kecil daripada tarif INA-CBGs. Komponen tagihan rumah sakit yang paling besar adalah Obat sebesar Rp.24.639.426 (63,05\%), selanjutnya Penunjang sebesar Rp.7.980.000 (20.42\%) dan tindakan sebesar Rp5.959.115 (15,24\%).

Tabel 1. Perbandingan tarif RS dan tarif INA-CBGs berdasarkan hypertensive heart disease with (congestive) heart failure

\begin{tabular}{clllc}
\hline No & \multicolumn{1}{c}{ Rincian Biaya } & Rata-rata/Pasien & Persentase (\%) & Ket \\
\hline 1 & Pendaftaran & Rp 500.000 & Rp 5.000 & 2,70 \\
2 & Tindakan & Rp 1.530.000 & Rp 15.300 & 49,60 \\
3 & Penunjang & Rp 28.043.387 & Rp 280.433,87 & 46,80 \\
4 & Obat & Rp 26.460.213 & Rp 264.602, 13 & Negatif \\
\hline Total Tarif RS & Rp. 56.533.600 & Rp. 565.336 & 66,44 \\
\hline \multicolumn{2}{l}{ Total Tarif INA-CBGs } & Rp. 18.970.400 & Rp. 189.704 &
\end{tabular}

Tabel 2. Perbandingan tarif rumah saki dan tarif INA-CBGs berdasarkan diagnosa Non-insulin-dependent diabetes mellitus

\begin{tabular}{clllc}
\hline No & & Rincian Biaya & Rata-rata/Pasien & Persentase (\%) \\
\hline 1 & Pendaftaran & Rp 500.000 & Rp 5.000 & 1,27 \\
2 & Tindakan & Rp 5.959.115 & Rp 59.591,15 & 15,24 \\
3 & Penunjang & Rp 7.980.000 & Rp 79.800 & 20,42 \\
4 & Obat & Rp 24.639.426 & Rp 264.394,26 & 63,05 \\
\hline Total Tarif RS & Rp. 39.078.541 & Rp. 390.785,14 & Negatif \\
\hline Total Tarif INA-CBGs & Rp. 19.553.100 & Rp. 195.531 & 49,96 \\
\hline Selisih & Rp. 19.525.441 & Rp. 195.251,41 & \\
\hline
\end{tabular}

Sumber : Data Rumah Sakit, 2017

Tabel 3. Perbandingan tarif rumah sakit dan tariff INA-CBGs berdasarkan diagnosa lower back pain

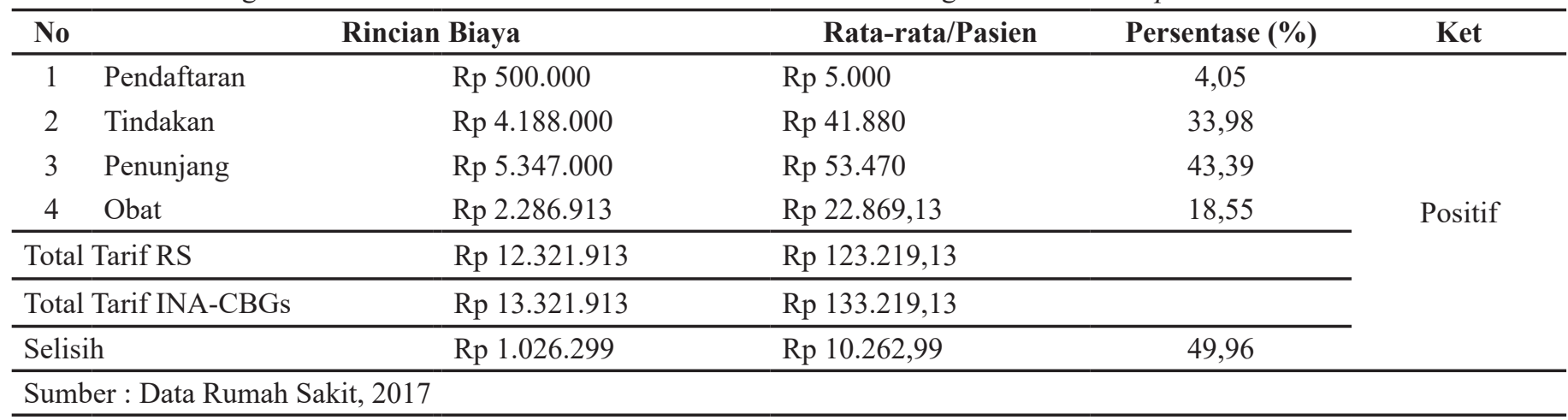


Tabel 4. Perbandingan tarif rumah sakit dan tarif INA-CBGs berdasarkan diagnosa atherosclerotic heart disease

\begin{tabular}{|c|c|c|c|c|c|}
\hline No & & Biaya & Rata-rata/Pasien & Persentase (\%) & Ket \\
\hline 1 & Pendaftaran & Rp 500.000 & $\operatorname{Rp} 5.000$ & 1,51 & \multirow{7}{*}{ Negatif } \\
\hline 2 & Tindakan & Rp 1.515.000 & $\mathrm{Rp} 15.150$ & 4,57 & \\
\hline 3 & Penunjang & Rp 7.130.000 & Rp 71.300 & 21,53 & \\
\hline 4 & Obat & Rp 23.959.035 & Rp 239.590,35 & 72,37 & \\
\hline \multicolumn{2}{|c|}{ Total Tarif RS } & Rp 33.104.035 & Rp 331.040,35 & & \\
\hline \multicolumn{2}{|c|}{ Total Tarif INA-CBGs } & Rp 19.984.800 & Rp 199.848 & & \\
\hline \multicolumn{2}{|c|}{ Selisih } & Rp 13.119.235 & Rp 131.192,35 & 49,96 & \\
\hline
\end{tabular}

Tabel 5. Perbandingan tarif rumah sakit dan tarif INA-CBGs berdasarkan diagnosa atherosclerotic heart disease

\begin{tabular}{|c|c|c|c|c|c|}
\hline No & & Biaya & Rata-rata/Pasien & Persentase (\%) & Ket \\
\hline 1 & Pendaftaran & Rp 500.000 & $\mathrm{Rp} 5.000$ & 2,57 & \multirow{7}{*}{ Positif } \\
\hline 2 & Tindakan & Rp 1.530 .000 & Rp 15.300 & 9,88 & \\
\hline 3 & Penunjang & Rp 3.550.000 & Rp 35.500 & 18,04 & \\
\hline 4 & Obat & Rp 13.816.431 & Rp 138.164,31 & 71,23 & \\
\hline \multicolumn{2}{|c|}{ Total Tarif RS } & Rp 19.396.431 & Rp 193.964,31 & & \\
\hline \multicolumn{2}{|c|}{ Total Tarif INA-CBGs } & Rp 21.799.600 & Rp 217.996 & & \\
\hline \multicolumn{2}{|c|}{ Selisih } & Rp 2.403.169 & $\operatorname{Rp} 24.031,69$ & 12,38 & \\
\hline
\end{tabular}

Sumber : Data Rumah Sakit, 2017

Tabel 6. Perbandingan total tarif rumah sakit dan total tarif INA-CBGs

\begin{tabular}{cllcl}
\hline No & \multicolumn{2}{c}{ Rincian Biaya } & (\%) & Ket \\
\hline 1 & Pendaftaran & $\operatorname{Rp~} 2.500 .000$ & 1,55 & \\
2 & Tindakan & $\operatorname{Rp~} 14.722 .115$ & 9,17 & \\
3 & Penunjang & $\operatorname{Rp~52.050.387}$ & 32,44 & \\
4 & Obat & $\operatorname{Rp~91.162.018}$ & 56,82 & \multirow{2}{*}{ Negatif } \\
\cline { 1 - 2 } Total Tarif RS & $\operatorname{Rp~160.434.520}$ & \\
\cline { 1 - 2 } Total Tarif INA-CBGs & $\operatorname{Rp~93.656.112~}$ & \\
\cline { 1 - 2 } Selisih & $\operatorname{Rp~66.778.404}$ & 41,62 & \\
\cline { 1 - 2 }
\end{tabular}

Sumber : Data Rumah Sakit, 2017

\section{Perbandingan tarif berdasarkan diagnosa Low back pain}

Low back pain (LBP) atau nyeri punggung bawah termasuk salah satu dari gangguan muskuloskeletal, gangguan psikologis dan akibat dari mobilisasi yang salah yang disebabkan oleh aktivitas tubuh yang kurang baik. Diagnosis LBP ditegakkan dari hasil anamnesis, pemeriksaan fisik umum dan khusus, serta pemeriksaan penunjang berupa pencitraan yang umum dilakukan[13].

Prevalensi LBP semasa hidup dipewrkirakan mencapai $84 \%$ dengan $23 \%$ pasien mengalami LBP secara kronik. Derajat nyeri yang disarankan dapat bervariasi dari ringan sampai cukup parah sehingga dapat mengganggu aktivitas sehari-hari individu, sekitar $11-12 \%$ pasien mengalami gangguan dalam beraktivitas akibat gejala LBP yang mereka alami[14].

Tabel 3. memperlihatkan secara total pada 100 pasien dengan diagnosis Low back pain menghasilkan selisih positif sebesar Rp. 1.026.299 (49,96\%) dengan empat kode INA-CBGs yang dibayarkan yaitu $37(3,7 \%)$ pasien dengan tarif rumah sakit lebih besar dari tarif INA-CBGs. Sementara sebanyak
$63(6,3 \%)$ pasien dengan besaran tarif rumah sakit lebih kecil dari tarif INA-CBGs. Komponen tagihan rumah sakit yang paling besar adalah penunjang sebesar Rp.5.347.000 (43,39\%), selanjutnya tindakan sebesar Rp.4.188.000 (33,98\%) dan obat sebesar Rp.2.286.913 (18,55\%).

\section{Perbandingan Kasus berdasarkan diagnosa Atherosclerotic heart disease}

Coronary Artery Disease (CAD) atau Penyakit Jantung Koroner (PJK) atau dalam ICD-X Atherosclerotic heart disease merupakan salah satu dari empat penyakit tidak menular utama WHO. Atherosclerotic heart disease (PJK) adalah kelainan yang disebabkan oleh penyempitan pembuluh arteri yang mengalirkan darah ke otot jantung, sehingga terjadi ketidakseimbangan antara suplai dan kebutuhan oksigen[14].

Atherosklerosis merupakan dasar patofisiologi PJK. Aterosklerosis adalah kondisi inflamasi kronis yang timbul dan perjalanan penyakitnya melibatkan lipid, komponen dinding vaskular, sistem imun dan trombosis[14].

Pada tabel 4. Memperlihatkan secara total pada 100 pasien yang di diagnosa Atherosclerotic heart disease menghasilkan selisih negatif sebesar Rp.13.119.235 dengan enam kode INACBGs yang dibayarkan yaitu Q-5-44-0 (Penyakit kecil lain lain), Q-5-43-0 (Penyakit Kronis Besar Lain-Lain), I-3-13-0 (Prosedur Ekokardiografi), I-3-14-0 (Prosedur Stress Testing), J-3-16-0 (Prosedur Uji Fungsi Paru), Q-5-42-0 (Penyakit Akut Kecil Lain - Lain). Sebanyak 73 (7,3\%) pasien yang besaran tarif rumah sakitnya lebih besar dari tarif INA-CBGs dan sebanyak $27(2,7 \%)$ pasien yang dibayarkan dengan tarif rumah sakit lebih kecil.

Komponen tagihan rumah sakit yang paling besar adalah obat sebesar Rp. 23.959 .035 (72,37\%), selanjutnya penunjang sebesar Rp.7.130.000 (21,53\%) dan tindakan sebesar Rp.1.515.000 (4,75\%). 


\section{Perbandingan tarif berdasarkan diagnosa Essential (primary) hypertension}

Hipertensi primer/ Hipertensi Esensial adalah hipertensi yang penyebabnya tidak diketahu (idiopatik), walaupun dikaitkan dengan kombinasi factor gaya hidup seperti kurang bergerak (inaktivitas) dan pola makan. Terjadi pada sekitar 90\% penderita hipertensi15. Pemeriksaan pasien dengan hipertensi harus dicari penyebabnya, namun perlu diingat bahwa penyebab paling umum yaitu hipertensi esensial/ tidak diketahui. Selain itu gejala penyakit maupun akibat pengobatannya juga harus diketahui. Sehingga perlu dilakukan pemeriksaan fisik dan laboratorium untuk mengetahui gejala dan akibat pengobatannya[16].

Pada tabel 5. Memperlihatkan secara total pada 100 pasien yang di diagnosis Essential (primary) hypertension menghasilkan selisih positif sebesar Rp. 2.403.169 dengan rerata Rp.24.031,69 (12,38\%). Terdapat 12 kode INA-CBGs yaitu Q-5-44-0 (Penyakit kecil lain - lain), I-3-13-0 (Prosedur Ekokardiografi), J-3-16-0 (uji Fungsi Paru), Z-3-23-0 (Prosedur Ultrasound Lain-Lain), Q-5-23-0 (Pemeriksaan Antepartum), Q-5-25-0 (Gastrointestinal Akut), M-3-16-0 (Prosedur Therapi Fisik Dan Prosedur Kecil Muskuloskletal), N-3-11-0 (Prosedur Diagnostik Lain Pada Studi Saluran Kemih), I-3-140 (Prosedur Stress Testing), Z-3-27-0 (Perawatan Luka), Q-527-0 (Sistem Saraf Pusat Akut), dan Q-5-42-0 (Penyakit Akut Kecil Lain - Lain). Sebanyak 39 (3,8\%) kasus yang besaran tarif rumah sakitnya lebih besar dari tarif INA - CBGs, yang berarti menghasilkan selisih negatif. Sementara sebanyak $61(6,1 \%)$ kasus dengan besaran tarif rumah sakitnya lebih besar dari tarif INA CBGS yang menghasilkan selisih positif. Komponen tagihan rumah sakit yang paling besar adalah obat sebesar Rp.13.816.431 dengan rerata Rp.138.164,31 (71,23\%), selanjutnya penunjang sebesar Rp.3.550.000 dengan rerata Rp.35.500 (18,04\%) dan tindakan sebesar Rp.1.530.000 dengan rerata Rp.15.300 (9,88\%).

\section{Pembahasan}

Perbedaan tarif yang terjadi di RSUD Pasar Rebo ditemukan pada perhitungan tarif rumah sakit dan tarif INACBGs. Perhitungan tarif INA-CBGs dalam bentuk paket yang didasarkan pada pengelompokan kode diagnosis (ICD-X) dengan menggunakan metode pembayaran prospektif. Metode pembayaran prospektif adalah metode pembayaran yang dilakukan atas layanan kesehatan yang besarannya sudah diketahui sebelum pelayanan kesehatan diberikan kepada pasien. Standar tarifnya sudah ditetapkan oleh Peraturan Menteri Kesehatan Republik Indonesia dan dibagi sesuai dengan regional wilayah dan tipe rumah sakit.

Sementara tarif rumah sakit dihitung menggunakan sistem pembayaran berdasarkan kebijakan tarif yang ditetapkan oleh Direksi Rumah Sakit dan mengacu pada Peraturan Gubernur menggunakan metode pembayaran retrospektif atau metode pembayaran yang dilakukan atas layanan kesehatan yang diberikan kepada pasien berdasar pada setiap aktifitas layanan yang diberikan.

Perbedaan tarif yang menguntungkan memang terjadi pada pihak rumah sakit. Penetapan tarif rumah sakit memperhatikan beberapa hal seperti kemampuan membayar masyarakat setempat, pelayanan rumah sakit ditetapkan atas dasar jenis pelayanan tingkat kecanggihan pelayanan dan kelas perawatan, memiliki cinta kasih yang tanpa batas dengan tetap memberi keringanan biaya pada pasien tidak mampu berdasarkan ketentuan yang ditetapkan oleh Direktur Jenderal Pelayanan Medik, adanya ikatan kerjasama dengan pihak BPJS dan selalu diperbaharui setahun sekali.

Perbedaan standar tarif yang terjadi akhirnya akan mempengaruhi besaran nominal tarif pelayanan kesehatan di RSUD Pasar Rebo yang rata - rata menghasilkan nilai selisih jika dibandingkan dengan nominal klaim JKN dengan menggunakan paket INA-CBGs.

Dari lima diagnosa terbanyak pelayanan rawat jalan, terdapat 3 diagnosa yang total besaran tarif rumah sakitnya lebih besar dari tarif INA-CBGs, yang berarti menghasilkan selisih negatif. Sementara sebanyak 2 diagnosa dengan besaran tarif rumah sakitnya lebih kecil dari tarif INA-CBGs, yang menghasilkan selisih positif. Dengan melihat presentase jumlah diatas kita dapat menyimpulkan rumah sakit "rugi" karena jumlah kasus dengan tarif rumah sakit yang lebih besar dari tarif INA-CBGs lebih banyak dari pada tarif rumah sakit yang lebih kecil dari tarif INA-CBGs.

Jumlah kasus pada tiga diagnosa memiliki tarif rumah sakit yang lebih besar dari tarif INA-CBGs. Sedangkan pada dua diagnosa lainnya memiliki jumlah kasus dengan tarif rumah sakit yang lebih kecil dari tarif INA-CBGs. Sehingga total selisih positif yang didapatkan dari kedua diagnosa tersebut tidak dapat menutupi besarnya selisih negative. Diagnosa yang menghasilkan selisih negative lebih banyak berasal dari poliklinik jantung. Hal ini sesuai dengan penelitian yang dilakukan oleh Dumaris (2015) yang menyatakan bahwa poliklinik jantung pada pasien rawat jalan menghasilkan selisih negative sebesar Rp.4.427.201.[17]

Pada lima diagnosa pelayanan rawat jalan terdapat tiga diagnosa dengan komponen tagihan terbesar yaitu biaya obat, dua diagnosa diantaranya yang memiliki tagihan paling tinggi adalah Atherosclerotic heart disease dan Non-insulindependent diabetes mellitus,. Sementara dua diagnosa lainnya tagihan terbesar pada pemeriksaan penunjang.

Pada tabel 6. Total keseluruhan tarif rumah sakit atau biaya yang dikeluarkan rumah sakit untuk memberikan pelayanan kesehatan pada pasien JKN selama satu tahun di unit pelayanan rawat jalan adalah Rp.160.434.520. Sementara total tarif INA-CBGs adalah Rp.93.656.112. Hal ini berarti total biaya pelayanan yang dikeluarkan rumah sakit untuk pelayanan rawat jalan sangat besar dibandingkan total yang dibayarkan BPJS dalam bentuk paket INA-CBGs. Rumah sakit mengalami kerugian sebesar Rp.66.778.404.

\section{Kesimpulan}

Terjadi perbedaan tarif rumah sakit dan tarif INACBGs dengan pembayaran lebih kecil dari tarif rumah sakit pada diagnosa Hypertensive heart disease with (congestive) heart failure, Non-insulin-dependent diabetes mellitus, Atherosclerotic heart disease. Dan terjadi perbedaan tarif rumah sakit dan tarif INA-CBGs dengan pembayaran lebih besar dari tarif rumah sakit pada diagnosa Low back pain dan Essential (primary) hypertension. Total selisih antara tariff rumah sakit dan tarif INA-CBGs adalah sebesar Rp.66.778.404. 


\section{Daftar Pustaka}

[1] Malik, R. (2000). PEMBIAYAAN KESEHATAN Dl INDONESIA TAHUN 1990-2000. Buletin Penelitian Sistem Kesehatan, 5 No.2, 94.

[2] Hosinah (2013). Case Mix Upaya pengendalian Biaya Pelayanan Rumah Sakit di Indonesia di unduh pada http://www.esaunggul.ac.id/article/case-mix-upayapengendalian-biaya-rumah-sakit-di-indonesia

[3] Kemenkes RI. (2013). Buku Pegangan Sosialisasi Jaminan Kesehatan Nasional dalam Sistem Jaminan Sosial Nasional. Departemen Kesehatan RI, 16-18, 21-29, 40-43, Kementerian Kesehatan Republik Indonesia, Jakarta

[4] Info BPJS (2016). Pentingnya Dukungan PEMDA untuk mencapai Universal Health Coverage. BPJS Kesehatan. Jakarta

[5] Forum, I. H. (2018). let's Make JKN Wins For All “ Harapan, Kenyataan \& Solusi JKN. Lembaga Penerbit Balitbangkes.

[6] Kementerian Kesehatan (2014). Info BPJS kesehatan Penetapan Tarif INA - CBGs edisi VIII. Jakarta

[7] Kementerian kesehatan Republik Indonesia. (2017). Laporan Pengelolaan Program dan Laporan Keuangan Jaminan Kesehatan Tahun 2017. Jakarta

[8] Rahayuningrun et al (2016). Comparison BetweenHospital Inpatient Costand INA-CBGsTarifof Inpatient Carein the National Health Insurance Schemein Solo, Boyolali and Karanganyar Districts, Central Java. Journal of Health Policy and Management 1(2): 102-112
[9] Suhartoyo (2018). Jurnal Administrative Law \& Governance Klaim Rumah Sakit Kepada BPJS kesehatan Berkaitan Dengan Rawat Inap Dengan Sistem INA CBGs. Semarang. Fakultas Hukum Universitas.

[10] Riaz, K, (2012). Hipertensive Heart Disease. Wright State University

[11] Ningrum,A.F.(2020).PENATALAKSANAAN HOLISTIK PADA PASIEN HYPERTENSIVE HEART DISEASE. JIMKI: Jurnal Ilmiah Mahasiswa Kedokteran Indonesia, 8(1), 104-115.

[12] Bare \& Smeltzer (2002).Buku Ajar Keperawatan Medikal Bedah Brunner \& Suddart (Alih Bahasa Agung Waluyo). Edisi 8 Vol.3. Jakarta : EGC

[13] M.Muhlis Rizki, (2020) . "Tatalaksana Medikamentosa Pada Low Back Pain" Fakultas kedokteran. Universitas Lampung, Lampung.

[14] Katzung,B. G (2002) Basic and Clinical Pharmacology, Edisi 8,317, McGeaw-Hill, Newyork.

[15]Kemenkes RI Pusat (2014). Pusat Data dan Informasi Hipertensi. Kementrian Kesehatan. Jakarta, Hal. 1

[16] Christy Dessy (2010). Gambaran Pengobatan Hipertensi Pada Pasien Rawat Inap Di Rumah Sakit Umum Pusat Dr. Soeradji Tirtonegoro Klaten Periode Januari-Juni Tahun 2009. Fakultas Farmasi Universitas Surakarta, Hal 7

[17]Hotma Dumaris (2016). Analisis Perbedaan Tarif Rumah Sakit dan Tarif INA-CBG's Pelayanan Rawat Jalan di RSUD Budhi Asih Jakarta Tahun 2015. Jurnal Administrasi Rumah Sakit. 3 (1). 